\section{A. ARS BILDUMA ISSN 1989-9262} ARSBILDUMA (CC BY-NC-ND 4.0)

https://doi.org/10.1387/ars-bilduma.18882 BIBLID [(2019), 9; 51-65]

Recibido: 20/12/2017 Aceptado: 19/07/2018

\title{
LA DESAPARECIDA TORRE-RELOJ DE SAN GIL DE GUADALAJARA. NUEVOS DATOS DOCUMENTALES SOBRE SU FÁBRICA Y MAESTROS DE OBRA
}

\author{
THE DISAPPEARED CLOCK TOWER OF SAINT GIL OF GUADALAJARA. NEW \\ DOCUMENTARY DATA ABOUT ITS CONSTRUCTION AND FOREMEN
}

\begin{abstract}
LA DisParue TOUR DE L'HORLOGE DE LA PAROISSE DE SAINT GIL DE GUADALAJARA. NOUVELLES DONNÉES DOCUMENTAIRES SUR CETTE CHANTIER ET SES MAÎTRES DE TAILLEURS DE PIERRES
\end{abstract}

\section{RESUMEN}

\section{RAÚL ROMERO MEDINA}

Universidad Complutense de Madrid

Facultad de Geografía e Historia Departamento de Historia del Arte

C/ Profesor Aranguren S/N

28040, Madrid (Madrid)

raul.romero.medina@ucm.es

ORCID ID: 0000-0001-6129-1399
Desde mediados del siglo XV el Concejo de la ciudad de Guadalajara disponía de un reloj en la torre de la parroquia de San Gil que asumía un valor simbólico y de representación ciudadana, como ocurrí en ciudades italianas y centroeuropeas. La fábrica de esta torre sufrió problemas estructurales durante los siglos de la Edad Moderna que motivaron un pleito que enfrentó a la ciudad con los beneficiados de la parroquia por su reparación. Este trabajo aporta nuevos datos documentales sobre su torre-reloj y los maestros de obra implicados en su transformación durant los siglos XVI y XVII, lo que permite conocer cómo era antes de desaparecer en el siglo XX.

PALABRAS CLAVE

Guadalajara; torre; reloj; San Gil; maestros de obra.

\section{ABSTRACT}

Since mid-fifteenth century Guadalajara City Council had a clock in the tower of Saint Gil's parish, which acquired symbolic value and representational status for its citizens in the fashion of Italian and Central European cities. The construction of this tower had some structural problems in the Modern Age, which led to a lawsuit and the consequent dispute between the city and the beneficiaries of the parish about its repair. This study provides new documentary data about the clock tower and the stonemasons involved in its transformation in the sixteenth and seventeenth centuries, allowing us to know what it looked like before it disappeared in the twentieth century.

KEYWORDS

Guadalajara; clock tower; Saint Gil; stonemasons.
RÉSUMÉ

$\mathrm{Au}$ milieu du XVe siècle, la mairie de la ville de Guadalajara disposait d'une horloge placée dans la tour de la paroisse de Saint Gil. Cette possession revêtait une valeur symbolique et incarnait l'idée d'une représentation citoyenne comme cela se passait dans les villes italiennes et d'Europe centrale. Durant l'Époque Moderne, cette tour connut des problèmes de structure. Les réparations donnèrent naissance à un procès entre la ville et les bénéficiaires de la paroisse. Ce dernier livra de nouvelles données sur la tour de l' horloge, les transformations survenues aux XVIe et XVIIe siècles, son état avant sa disparition au XXe siècle et sur les maîtres tailleurs de pierre impliqués dans ces travaux.

MOTS-CLÉS

Guadalajara; tour; horloge; Saint Gil; maîtres de tailleurs de pierre. 
1. LA CIUDAD MEDIEVAL Y LA PARROQUIA MUDÉJAR DE SAN GIL

A mediados del siglo XV la ciudad de Guadalajara gozaba de una posición predominante en la Corona de Castilla que la situaba como una de las principales villas de señorío real. Los privilegios con los que los monarcas la dotaron permitieron un desarrollo económico que consolidó un caserío provisto de cinturón defensivo y alcázar. Su configuración urbana intramuros era heredera de un sistema medieval que la había articulado administrativamente en diez collaciones, representadas por las parroquias de San Andrés, San Julián, Santo Tomé, San Esteban, San Miguel, Santa María, San Ginés, San Gil, San Nicolás y Santiago ${ }^{1}$.

En la vista panorámica de la ciudad dibujada por A. Wyngaerde en 1565 quedan reflejadas algunas de estas parroquias y se aprecian sus estructuras medievales acordes con un arquitectura que combinaba las hiladas de ladrillo con la mampostería de piedra caliza al "estilo mudéjar"2. Aunque no era la más alta e importante, pues este privilegio lo tenía la de Santa María, destaca por encima del abigarrado caserío urbano la torre de la parroquia de San $\mathrm{Gil}^{3}$ por encontrarse en el punto más alto de la ciudad ${ }^{4}$ (Fig.1).

Los aledaños de la parroquia de San Gil se habían convertido en el epicentro de la vida urbana de la Guadalajara medieval. Los datos aportados por Layna Serrano prueban que e Concejo se reunía en su puerta o atrio para ayuntar a sus regidores en la toma de decisiones,

1 LAYNA SERRANO, F.: Historia de Guadalajara y sus Mendozas en los siglos XV y XVI. Tomo I, segunda edición. Guadalajara, AACHE ediciones, 1993, pp. 89-131 y PAVON MALDONADO, B.: "Guadalajara medieval. De la ciudad árabe a la cristiana. Testimonios arqueológicos”, en MITRE, E, BALLESTEROS, P y PAVON, B. (eds.): IX Centenario de la conquista de Guadalajara. Guadalajara, Patronato Municipa de Cultura de Guadalajara, 1988, pp. 27-52.

SÁNCHEZ CASTRO, J.: "Mudejarismo en Guadalajara (siglos XIII-XV)", Wad-al-Hayara, 12, 1995, pp. 145-156.

PRADILLO Y ESTEBAN, P.J.: "La desaparecida parroquia de San Gil de Guadalajara: Estado de la cuestión y nuevas aportaciones". Wad-al-Hayara, 21, 1994, pp. 211-256 y TRALLERO SANZ, A.M. "La iglesia de San Gil de Guadalajara". Archivo Español de Arte, LXXXVIII, 350. 2015, pp.113-130. L noticia más antigua de su existencia es anterior a 1226 cuando el monarca Fernando III confirma una donación de casas y viñas de don Egidio, presbítero de San Egidio (San Gil), al monasterio de monjas dominicas de Madrid. Cfr. PÉREZ DE TUDELA, Ma. T.: "Madrid en la documentación de Santo Domingo el Rel", en SÁEZ SÁNCHFZ, E Y SEGURA GRÁÑ XIII al XVI. Madrid, Universidad Complutense de Madrid, 1985, pp. 991-1010.

4 MUÑOZ JIMÉNEZ, J. M.: "Iconografía y topografía: análisis de la Vista de Guadalajara de Antonio de las Viñas y de otras dos vistas barrocas sobre lo mismo", Actas del III Encuentro de Historiadores de Valle del Henares. Guadalajara, Diputación Provincial de Guadalajara, 1992, pp. 673-689.

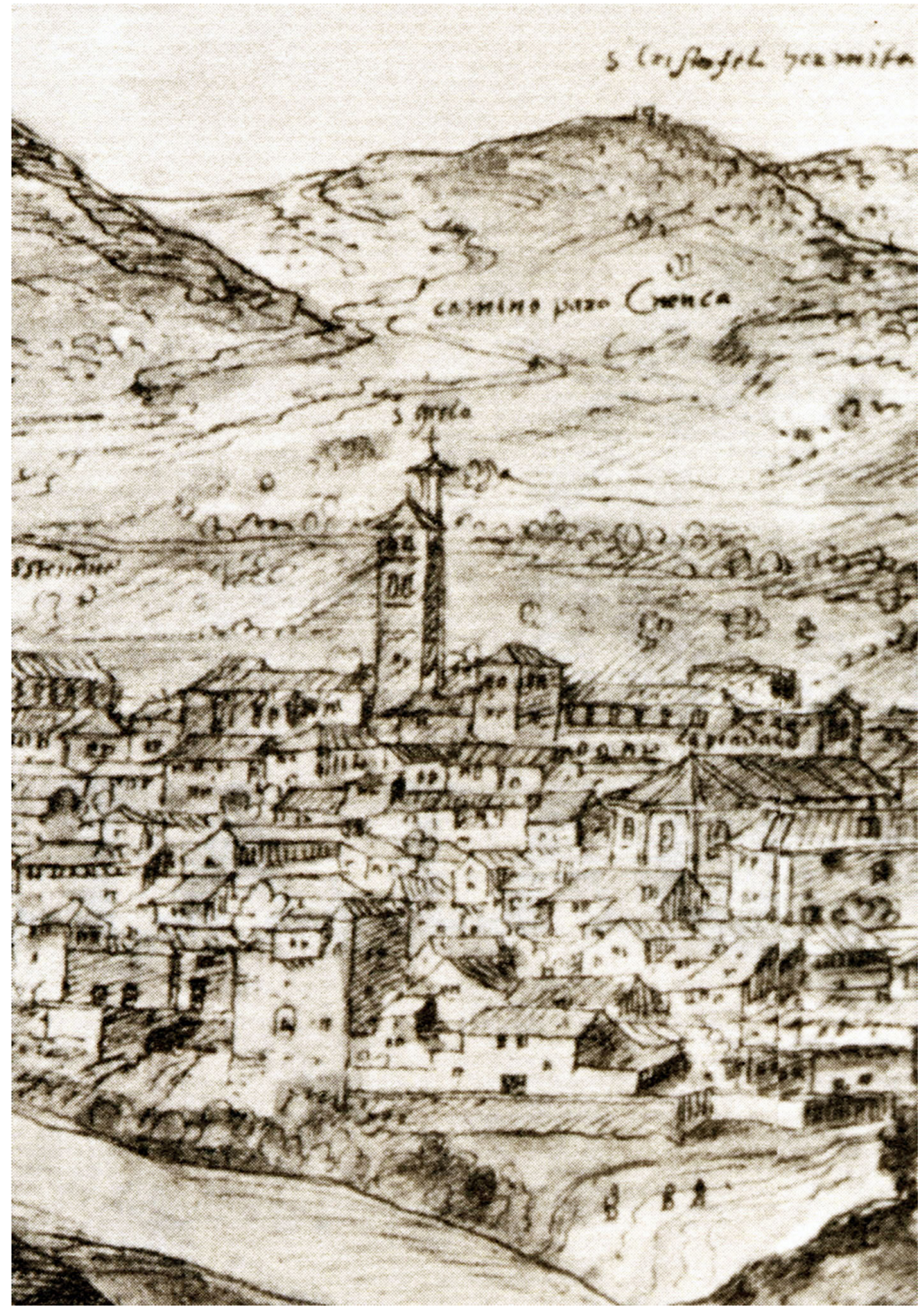

Fig. 1: Torre de San Gil en las vistas de la ciudad de Guadalajara. A. Wyngaerde, 1565. https://es.wikipedia.org/wiki/Archivo:Anthonis_van_den_Wijngaerde_(1565)_Guadalajara.png 
siendo el testimonio más antiguo del año de $1376^{5}$. Aunque en 1427 consta que el Concejo disponía ya de una cámara, los acuerdos tomados seguían leyéndose en San Gil, si bien, en 1463 se hicieron en Santo Domingo el Viejo y en 1483 en San Andrés $s^{6}$ La publicación de las actas del concejo medieval de la ciudad nos ha permitido conocer con más exactitud los espacios que este eligió para sus intervenciones públicas, entre 1454-15007. De ello se deduce que la iglesia de San Gil y su pórtico fue un enclave muy ocasional para la reunión del cabildo municipal ${ }^{8}$ si bien importante simbólicamente por su torre.

Aunque en el siglo XV el cabildo disponía de un edificio propio en una plaza mayor de estructura cuadrada y soportales, de tiempos del Cardenal Mendoza, estas casas consistoriales estuvieron en pie hasta su demolición en $1585^{\circ}$, momento en el que se levantó un edificio dotado con galería alta de arcos de medio punto con columnas clásicas y torreta para ubicación de un reloj. Aunque esa torreta nunca debió contener el reloj, el edificio fue completamente remodelado en el siglo XVIII ${ }^{10}$

Los orígenes de la fábrica de San Gil datan de principios del siglo XIII, si bien debió ser concluida en los siglos XIV y XV. Torres Balbás la relaciona por el estilo de su ábside con el foco mudéjar toledano ${ }^{11}$. Pradillo y Esteban ${ }^{12}$ señala que su origen fue un templo de tres

LAYNA SERRANO, F.: op.cit. p.58 (Tomo 1.1)

$6 \quad$ Ibid. p.353 (Tomo 1.2)

Estos espacios eran la iglesia de Santo Domingo, el alcázar real, la iglesia de San Andrés, la iglesia de San Gil o la plaza del concejo o plaza de Santo Domingo. Se puede incluso tomar el pulso al número de reuniones y es San Gil el que queda en último lugar. Cfr. LOPEZ VILLALBA, J.M.: Las Actas de Sesiones del Concejo Medieval de Guadalajara. Madrid, Universidad Nacional de Educación a Distancia, 1997, pp. 63 y ss.

8 Algo que ya apuntó PRADILLO Y ESTEBAN, P.J.: "Organización del espacio urbano en la Guadalajara medieval', Wad-al-Hayara, 26, 1999, pp. 17-55.

9 Siendo alcalde el licenciado Bobadilla se autorizó este derribo. LAYNA SERRANO, F.: op.cit. pp. 295 296 (Tomo 1.3.). El nuevo edificio debió acabarse hacia 1595, pues el 28 de abril se decidió labrar un pasadizo exterior que comunicara el ayuntamiento con la cárcel. Cfr. MUÑOZ JIMÉNEZ, J.M.: "De la ciudad medieval a la ciudad del Siglo de Oro: análisis de la transformación urbanística y arquitectónica de Guadalajara (1550-1650)", Wad-al-Hayara, 13, 1986, p. 367.

10 QUADRADO FUENTE, M. a: Guadalajara y Cuenca. Barcelona, Ediciones el Albir, 1978, p.44. Este autor señala que en 1716 se añadió al edificio de forma mezquina la moderna torre del reloj y dos cuerpos laterales.

11 TORRES BALBÁS, L.: "Arte almohade, arte nazarí y arte mudéjar", Ars Hispaniae, IV. Madrid, Plus Ultra, 1949.

12 PRADILLO Y ESTEBAN, P.J.: “La desaparecida parroquia...," pp. 211-256. naves que se vio transformado en la ampliación del trescientos en uno de nave central con capillas laterales comunicadas por arcos independientes. El citado autor afirma que en estas obras se renovaron las cubiertas y se adaptó el muro de los pies a la nueva distribución donde se abrió una puerta con arco de herradura apuntado. Del mismo modo, incluye la obra de la torre en la ampliación del siglo XIV, aunque no deja claro si existió otra primitiva.

Por su parte, Sánchez de Castro ${ }^{13}$ la define como de una sola nave, cubierta con techumbre de madera y dotada con ábside semicircular con bóveda gallonada, y le presupone dos puertas de acceso, una a mediodía y otra a poniente que daba a un pórtico sobre cuatro columnas. Respecto a su torre anexa a la cabecera, a la que se accedía por la capilla mudéjar de los Orozco, la describe como prismático-cuadrangular cubierta con tejado a cuatro vertientes sobre modillones de rollo.

Trallero Sanz ${ }^{14}$ se aproxima a través de un minucioso análisis de la documentación gráfica conservada y sostiene que en origen la iglesia era de tres naves, y a pesar de haber recibido alguna reconstrucción parcial, fue en el siglo XVII cuando su espacio se vio profundamente alterado con la construcción de bóvedas interiores que ocultaron la estructura mudéjar primitiva, transformando las tres naves en una única con capillas laterales. En el presbiterio se sustituyó la bóveda de cañón por una semiesfera con linterna. Respecto a su torre afirma que se trata de la obra primitiva y de estructura prismática sin núcleo central. Por último alude a la construcción de un atrio en el siglo XVI que debió sustituir a otro anterior. En este estado permaneció hasta su orden de derribo en $1924^{15}$ (Fig.2).

3 SANCHEZ CASTRO, J.: op.cit. pp.145-156.

14 TRALLERO SANZ, A.M.: op.cit. pp. 113-130.

15 En el informe que se pidió a la Academia antes de su completa demolición, el 22 de agosto de 1924 don Ramón Mélida afirmaba. "Hay indicios de que la Iglesia de San Gil, en Guadalajara debió ser construcio MV quedaron de habrica primitiva la portada principal y na hacer dicha obra y ambas de gusto mudéjar". Informe sobre la iglesia de San Gil, de Guadalajara. José Ramón Mélida y Alinari. Real Academia de Bellas Artes de San Fernando. Comisión de Monumentos Exp. CAGU/9/7956/19(5) 


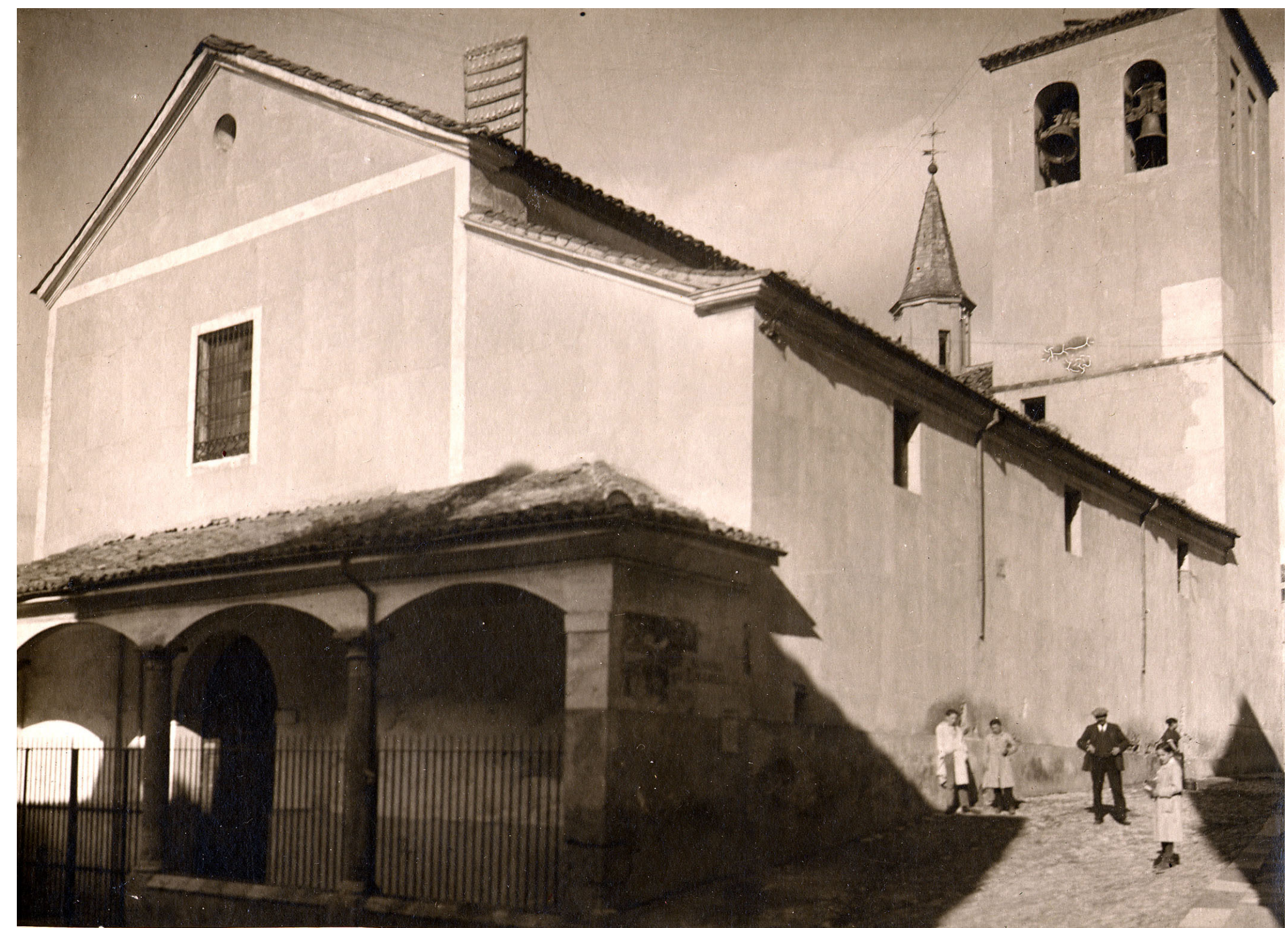

Fig. 2: Iglesia de San Gil. Vista General. Fotografía de Ángel Arquer. Positivo de época sobre cartón, c. 1920, 13 x 18 cms. Colección de Pedro José Pradillo y Esteban, nº 0572 


\section{EL TIEMPO SE HACE LAICO: EL RELOJ DE LA TORRE DE SAN GIL}

Como podemos comprobar la historiografía, deja claro que la torre corresponde a un ejemplar mudéjar que relacionan con el modelo de la iglesia de Santa María. Se trataba de una torre de planta rectangular provista de gruesos muros con doble cuerpo de vanos y una torrecilla que hacía de campanil. El muro de la torre se apoyaba en el testero de la iglesia y en el arco de un frustrado crucero y contenía una falsa bóveda para el apoyo de su escalera. La finalidad del cuerpo inferior era alojar la escalera que permitía subir al segundo cuerpo de dobles vanos donde se encontraba la maquinaría del reloj y desde aquí al campanil. Al igual que la torre de Santa María contaba al exterior con sus ventanas primitivas ligeramente rehundidas que presentaban alfiz y era rodeada a media altura por una línea de imposta. Por tanto, hemos de suponer que la torre de San Gil era un ejemplar mudéjar que correspondía a la edificación primitiva, si bien sufrió reformas en el cuatrocientos, para colocar el reloj, y en los siglos posteriores, como veremos. En cualquier caso, la imagen que presentaba antes de su derribo, con excepción del chapitel barroco, era muy parecida a la conservada de Santa María (Fig. 3).

A pesar de ser Santa María la fábrica más importante, la torre de San Gil se va a convertir en un caso peculiar para la ciudad, ya que en ella se instaló el reloj "por ser el sitio mas alto de esa dicha çibdad y en mitad della y no aber otra parte mas comoda y mejor donde pudiese estar"16. Esta situación resulta un tanto atípica al mezclarse los poderes civiles y religiosos en un mismo edificio, pues como afirmaba Le Goff, el tiempo laico se impone en la era humanista frente al tiempo clerical de las campanas de la iglesia ${ }^{17}$. No obstante, no se trata del único caso conocido, pues también ocurrió en la iglesia de San Salvador de Madrid ${ }^{18} \mathrm{O}$ en la de Santa Cruz en Medina de Rioseco ${ }^{19}$. Además, aunque estuviesen colocados en templos, al ser de utilidad pública eran sufragados por los concejos municipales.

16 Felipe II al concejo de la ciudad de Guadalajara, 15 de febrero de 1567, Archivo Histórico Nacional, Madrid (AHN), Sección Clero Secular-regular, Legajo 2109.

17 LE GOFF, J.: La civilización del occidente medieval. Barcelona, Paidós, 1999.

18 BENITO RUANO, E.: "Relojes y relojeros del ayuntamiento de Madrid en los siglos XV y XVI", Anales del Instituto de Estudios Madrileños, T.III, 1968, pp. 141-149.

19 REDONDO CANTERA, M. ${ }^{a}$ J.: "El reloj de la iglesia riosecana de Santa Cruz, obra de maestros burgaleses", Boletín de la Institución Fernán González, 212, 1996, pp. 99-106.

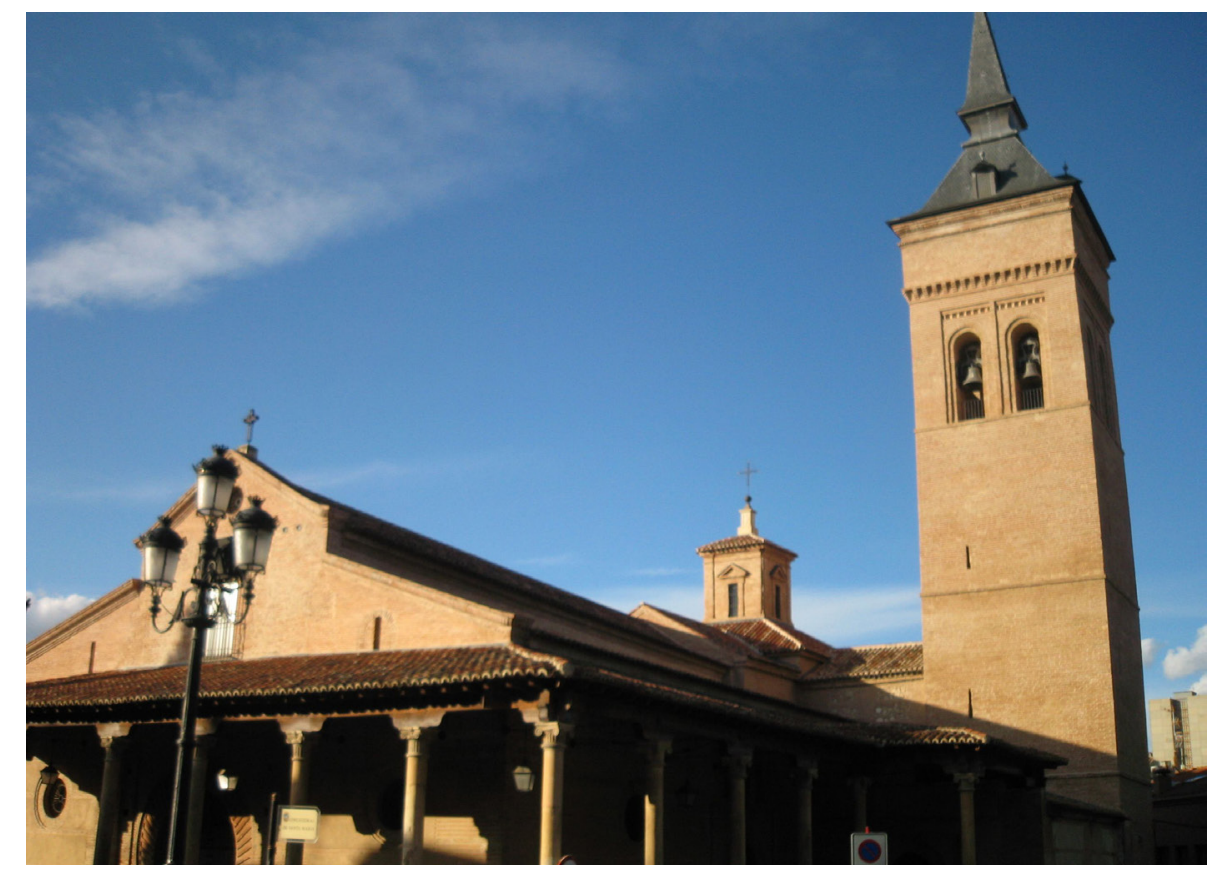

Fig. 3: Concatedral de Santa María de Guadalajara

En el caso de Guadalajara, si en San Gil se ayuntaba el cabildo era lógico pensar en su torre para la instalación del reloj, pero sobre todo se debió tener en cuenta por ser el punto más alto para que el sonido llegase a todos los rincones de la ciudad. Desconocemos en qué fecha el Concejo pudo ordenar la hechura e instalación del mismo o quién fue su autor ${ }^{20}$,

20 No hay noticias del reloj en las actas del Concejo entre 1454 y 1500. Ello nos permite plantear la hipótesis de que la instalación se pudo realizar antes de 1454. Pudo realizarse con posterioridad a 1500 pero resulta contradictorio respecto a lo que se describe en 1567 cuando se dice que está desde tiempo inmemorial. Aunque Mejía Asensio aporta datos sobre los maestros de obra activos entre 1491 y 1531 no da información sobre un posible rejero y atribuir la obra de la torre sin documentación precisa no da inormán a uno de estos mestos resultanla cuanto nenos arbitratio por nuestra parte. Cfr. ME) IA ASENSIO, A.: "Apuntes para una mejor comprensión de la evolución urbana de la ciudad de Guadalajara en los inicios de la Edad Moderna (1491-1531)", Actas del XI Encuentro de Historiadores del Valle del Henares. Guadalajara, Diputación Provincial de Guadalajara, 2008, pp. 553-576. 
pero sí que estaba en dicha torre "de tiempo inmemorial". Por ello, la torre pronto debió de convertirse en un monumento de orgullo ciudadano, como en el caso de las ciudades italianas de Siena o Bolonia o centroeuropeas de Praga y Cracovia, llegando a tener un relojero a sueldo para su costoso mantenimiento.

En los últimos años de la Edad Media estos aparatos fueron proliferando por toda Europa haciéndose cada vez más complejos ${ }^{21}$. Aunque sería aventurarse en la datación, podemos pensar que el ejemplar de San Gil pueda fecharse a finales del siglo XV, momento en el que la torre mudéjar pudo ser ampliada con una reforma en el segundo cuerpo y campanil, como se ve ya en las citadas vistas de 1565 . El cuerpo inferior de la torre tenía la finalidad de alojar la escalera y permitía ascender al segundo nivel que era doble y donde se alojaba la maquinaria del reloj. Por encima se localiza la torrecilla, a la que se podía acceder mediante una trampilla, donde se ubicaba el campanil.

Si tenemos en cuenta que el reloj debió tener un volumen considerable, pues su estructura era de madera y hierro, éste debía de necesitar un espacio para colocar la máquina, es decir ese segundo cuerpo. Como tendremos ocasión de estudiar, el informe que presentaron en Cabildo sobre las obras necesarias para evitar el estado ruinoso de la torre, en ese mismo año de 1565 y posterior de $1566^{22}$, nos ofrece pistas sobre cómo era la estructura y la ubicación de ese reloj.

Así las cosas, el reloj tenía una campana para dar la hora ubicada en el campanil. Su moto estaba formado por pesas y cadenas alrededor de las ruedas que se iban desenvolviendo. Desconocemos, como ocurre en otros casos españoles, si la esfera contenía alguna decoración llamativa, pero sí tenemos documentada la presencia en el reloj del "hombre de lata", es decir, un autómata que salía a determinadas horas del día como en los casos de Praga, construido en 1490 por Hanush, el de los célebre "moros" de San Marcos de Venecia, datado en 1493, o el fabricado en la localidad umbra de Orbieto a finales del siglo XV. En Castilla tenemos los casos de Burgos, con el Papa-Moscas y Martinillo añadido en 1519 o los de Astorga, Palencia o Medina del Campo ${ }^{23}$. En Andalucía destacan los desaparecido

21 ARACIL, A.: Juego y Artificio. Madrid. Cátedra, 1998, pp. 61 y ss.

22 Sobre los reparos que son necesarios acometer en la torre de San Gil, 30 de julio de 1565 y 9 de octubre de 1566, AHN. Sección Clero Secular-regular, Legajo 2109. Apéndice documental, documento 1 23 ARACIL, A.: op.cit. pp. 63 y ss. ejemplares de reloj de la Torre de la Atalaya, de Jerez de la Frontera, obra del relojero francés Fernando Guillén que tuvo su "onbre de armas"24 o Cádiz, cuyo reloj estaba ubicado en el castillo y fue realizado en 1525 por el entallador afincado en Jerez Francisco de Heredia ${ }^{25}$.

No nos constan datos documentales sobre el mantenimiento del reloj, pero sí que debido a su pesadez provocó ciertos problemas de estructura en la torre, lo que enfrentó al cura y beneficiados de la parroquia con el Concejo entre los años 1565 y 1567. El reloj debió estar en funcionamiento hasta el siglo XVIII, momento en el que fue trasladado al edificio que entonces tenía el Concejo en la plaza mayor de la ciudad, no sin polémica entre las partes ${ }^{26}$.

\section{EL PLEITO POR SU REPARACIÓN Y LA VISTA DE MAESTROS JUAN} DE RIAZA, JUAN DEL CAMPO Y ACACIO DE OREJÓN

En el mismo año de 1565 en el que Wyngaerde visitaba Guadalajara e ilustraba su vista con el bello y estilizado perfil de la torre de San Gil, su fábrica ya planteaba serios problemas estructurales que la hacían amenazar ruina. Esta situación llegó a enfrentar durante unos años al cura y beneficiados de la parroquia con el Concejo de la ciudad en un litigio que necesitó la mediación del mismo Felipe II. Como hemos señalado, el reloj del Concejo se ubicaba en la citada torre, si bien este pagaba una suerte de renta mensual a la iglesia fijada en 600 maravedíes. La estructura del reloj y el peso de la campana, más bien un campanil mal construido, había sido el culpable de que la torre mudéjar amenazara ruina. Por ello, el cura de San Gil, Marcos Gómez, exigía su reparación y prohibía su entrada al Concejo mientras no se pusiera remedio al deterioro de su fábrica.

Como era habitual en estos casos, se solía llamar a maestros para que dieran su parecer, una suerte de peritaje, sobre el estado en el que se encontraba la fábrica. El 30 de julio de 1565 el Concejo guadalcarreño trataba este asunto en cabildo y pedía a los regidores Francisco

24 ROMERO BEJARANO, M.: Santas cosas son llamadas los muros. La arquitectura militar en Jerez duran te el siglo XVI. Jerez de la Frontera, Servicio de Publicaciones del Ayuntamiento de Jerez de la Frontera. 2008, p. 121.

25 ROMERO BEJARANO, M.: "Francisco de Heredia, maestro entallador, y la autoría del Cristo de la Viga de San Salvador de Jerez de la Frontera", Laboratorio de Arte, 16, 2003. pp. 381-398.

26 Traslado del reloj, 12 de enero de 1788, Archivo Municipal de Guadalajara, Guadalajara, Libro de Actas del Consejo. Según Pradillo y Esteban la iglesia cedió confiando en recibir ayuda económica para el reparo del edificio, contraprestación que nunca se hizo efectiva. Cfr. PRADILLO Y ESTEBAN, P.J.: "La desaparecida parroquia...," p. 219 
de Guzmán y López de Lasarte que averiguasen el asunto. El documento incluye, como analizaremos detenidamente, un parecer, probablemente dado por los alarifes del cabildo, con las condiciones para el pregón y adjudicación de la obra.

Por su parte, el 12 de septiembre de 1565 el cura de la iglesia nombraba a los maestros Juan del Campo y Juan de Riaza "el de Santo Tomé" quienes, días más tarde, el 7 de octubre de dicho año, confirmaban que la ruina que amenazaba la torre estribaba en el peso que tenía la campana y el reloj, además del tejado que la cubría. No cabe duda de que el peso de la campana y las vibraciones, junto un campanil mal construido, debieron incidir en la ruina de la fábrica. Hay que tener en cuenta que el muro de la torre se apoyaba sobre el testero de la iglesia y ello podía traer consecuencias sobre el ábside del templo. El parecer recomendaba reforzar el cuerpo de la torre para impedir su caída ya que "el pilar que esta hacia el corral es delgado y esta destrabado"27. Todo ello quedaba estimado en 20.000 maravedíes.

Junto a ello, el 31 de diciembre de 1565, los maestros Acacio de Orejón y Juan de Riaza "el de San Ginés" examinaban la obra y remarcaban esta misma situación de amenaza de ruina debido al peso del reloj. Los mismos advertían que si no se hacía con brevedad podría ocurrir una desgracia, por lo que invitaban a los alarifes de la ciudad a que dictaminasen su remedio y reparo.

No sabemos si la distinción entre dos maestros Riaza, que trabajan en las parroquias de San Ginés y Santo Tomé, respectivamente, nos puede poner ante la presencia de dos maestros. En cualquier caso, Juan de Riaza, vecino de Guadalajara, está documentado desde 1549 como maestro de obras de albañilería y carpintería en la iglesia de San Julián ${ }^{28}$. A partir de 1568 se muestra como examinador de obras en la ciudad y en 1570 presentó postura para la obra de los entresuelos del palacio del marqués de Montesclaros, según condiciones de Acacio de Orejón, aunque finalmente fueron rematadas en Francisco de Paz y Alonso de Bustares por asumirlas a la baja ${ }^{29}$. En 1590 se documenta un Juan de Riaza, que Muñoz

27 Parecer de los maestros de obra Juan del Campo y Juan de Riaza, 12 de septiembre de 1565, AHN. Sección Clero Secular-regular, Legajo 2109.

28 MUÑOZ JIMÉNEZ, J.M.: La arquitectura del manierismo en Guadalajara. Guadalajara, Institución Provincial de Cultura "Marqués de Santillana", 1987, p. 193

29 MUÑOZ JIMÉNEZ, J.M.: “La arquitectura del manierismo..., p.193.
Jiménez señala como hijo de este primero, junto con Antonio Manrique para hacer una noria en la huerta de Francisco de Ávalos. Quizá los dos maestros apellidados Riaza que emiten informes en San Ginés fueran padre e hijo ${ }^{30}$.

Por su parte, Acacio de Orejón es un conocido maestro de Guadalajara, documentado entre 1519 y 1574, hijo del albañil Íñigo de Orejón, de procedencia morisca, y al que se le debe la reforma del Palacio del Infantado, como maestro de obras del duque ${ }^{31}$.

En último lugar, Juan del Campo un maestro bien documentado en Guadalajara entre 1569 y 1578 en torno a las obras de reforma del Palacio del Infantado y a la construcción del colegio de Nuestra Señora del Remedio, entre otras obras realizadas en la misma cuadrilla ${ }^{32}$.

El 9 de octubre de 1566 tenemos otra redacción de condiciones que incluía otra cláusula más en la que se amplía la obra de refuerzo que debía de ejecutarse en la torre. No sabemos quiénes fueron los maestros en los que se remató la obra tras el pregón de las condiciones, pero sí que se debió realizar con posterioridad al 15 de febrero de 1567, cuando Felipe II instaba encarecidamente al Concejo de Guadalajara a su reparo ${ }^{33}$.

30 ÍDEM

11 GARCÍA LÓPEZ A. "Datos artísticos inéditos sobre el maestro de obras morisco Acacio de Orejón (1519-d.1574)", Wad-al-Hayara, 20, 1993, pp. 265-290.

32 MUÑOZ JIMÉNEZ, J.M.: "La arquitectura del manierismo..., pp. 196-197.

33 "Don Phelipe por la gracia de Dios rey de Castilla etc., Salud e Gracia. Bien sabeis como por una nuestra carta dada vuestro pedimento mandamos a nuestro corregidor de esa ciudad enbiase ante los del nuestro consejo relacion sobre que estando esa dicha ciudad de tiempo inmemorial a esta parte es costumbre tener un relox en la torre en la yglessia de San Gil della por ser sitio mas alto de esa dicha ciudad y en mitad della y no aber otra parte mas comoda y mejor donde pudiese estar para lo qual aviase tenido para siempre un rexero con salario $y$ estando en la dicha posesion el cura $y$ clerigos de dicha a rian cerrado la puerta de ha dicha torre y nocon a regir e gobenar el dicho relox cono constaba por cierta ynormacion de que ante los del nuestro consejo fue fecha presentacion segun que mas largamente la dicha nuestra probision se contenia en cumplimiento de la qual el dicho nuestro corregidor enbio la dicha relacion e por los del nuestro consejo visto y cierta informacion e testimonio fue acordado que debiamos mandar esta nuestra carta para vos en la dicha razon nos tubimosla por bien porque vos mandamos que luego esta nuestra carta fuere mostrada dereceis y repareis la dicha torre de la yglessia de San Gil de esa dicha ciudad donde esta el dicho relox conforme a la declaracion hecha por los maestros nombrados para ello y en el entretanto por esta nusta carta la declacion hech por los mos de rona sientan entrar en la dicha tore abeneziar eldihorelox a la persona opersonas que para eflo tureredes nombradas de lo qual mandamos dar e dimos esta nuestra cara sellada con el nuestro sello e librada de los del nuestro consejo. Dada en Madrid a quinze dias del mes de hebrero de myll e quinientos e sesenta e siete años. El Licenciado Diego de Espinosa el Licenciado Diego Gascon el Licenciado Pero Gascon e 
Este pliego de condiciones resulta revelador porque nos da datos sobre el reloj y las reparaciones a realizar en la obra, si bien su interpretación resulta compleja. En él se contienen seis condiciones para que el maestro a quién se adjudicase la hiciese a toda costa acabada en su perfección a vistas de los maestros que fuesen llamados.

De la primera condición se deduce que la torre tenía grietas, deformaciones de los vanos, por lo que se recomendaba macizar los arcos. Además de agrietamientos en las esquinas, con desprendimientos y separación de estas, por lo que el maestro estaba obligado a hacer "sus ligaçones en lo viejo muy acusado al remate maçiçando todos los agujeros que oviere en esta esquina de yesso y ladrillo muy maçiço"34.

La segunda, tercera, cuarta y sexta condición deben ser interpretadas como obras de refuerzo en la torre con detalladas recomendaciones destinadas a consolidarla y reforzar su estabilidad geométrica al trabarla con vigas de madera, lechadas de yeso y canto y clavazones de hierro para fijarlas, junto con quadrales. De la interpretación de estas condiciones se deduce que había que hacer una suerte de armadura de cubierta de vigas bien armadas con maderos o cuadrales que en las esquinas hacían la función de unir dos estribos perpendiculares entre sí. Además, había que macizar desde el grueso de los arcos a la viga con una tercia de yeso y canto o de yeso y ladrillo "lo que el maestro que esta obra hiciere quisiere echar" ${ }^{\prime 3}$. Por último, era necesario retejar la cubierta de la torre.

En ningún momento se hace alusión a la maquinaria del reloj, tampoco a sus cadena o poleas "que subían cerca de unos arcos quebrados". Entendemos que estaba en buenas condiciones, pero sí se recomienda aderezar el tabladillo, es decir, la estructura de madera sobre la que se ubicaba la maquinaria, además de guarnecer la lata del autómata al que había que fabricarle unas nuevas piernas de madera junto con "todas las cosas que fuere

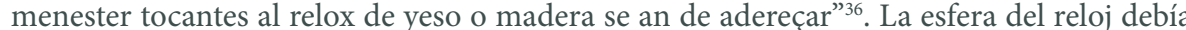

Licenciado Fuenmayor y el doctor Francisco Hernandez de Liebana y Domingo de Cabala escriuano de camara de Su Magestad la fize escriuir por su mandado con aquerdo de los del su consejo. Registrada Martin de Vergara. Martin de Vergara por Chanciller". Felipe II al concejo de la ciudad de Guadalajara, 15 de febrero de 1567, AHN, Sección Clero Secular-regular, Legajo 2109

34 Sobre los reparos que son necesarios acometer en la torre de San Gil, 30 de julio de 1565 y 9 de octubre de 1566, AHN. Sección Clero Secular-regular, Legajo 2109. Apéndice Documental, documento 1. Ibid.

36 Ibid. de estar colocada en un lugar visible, probablemente por encima de la cornisa que separaba os dos cuerpos de la torre, pues el documento señala "encima del can donde esta el relox" ${ }^{37}$ Por ello, se trata de una mera hipótesis.

Desconocemos el maestro que llevó a cabo estas intervenciones, alguien diestro en albañilería y cantería, pero debieron ejecutarse en 1567, después de la ejecutoría de Felipe II, salvando la ruina que amenazaba la torre.

\section{SU TRANSFORMACIÓN EN EL SIGLO XVII Y EL REMATE DE LOS MAESTROS DIEGO DE YEBES Y SEBASTIÁN PÉREZ}

En 1668 Pier Maria Baldi, pintor y arquitecto, que formaba parte del séquito del viaje que Cosme III de Médicis realizaba por toda Europa, pintaba una hermosa acuarela con vista de la ciudad en la que nos presentaba una transformada y barroca Guadalajara. En la parte más baja de la ciudad, hacia la derecha y haciendo una lectura desde fuera hacia dentro, destacan el torreón del alamín, la torre de la iglesia de Santa María, la torre de San Gil y la torre de San Andrés. Es curioso que estas tres torres presentan una fisonomía muy diferente a la dibujada por Wyngaerde, pues la de Santa María está coronada por un chapitel, la San Gil ha perdido el campanil, un cuerpo de campanas y está coronada por chapitel y la de San Andrés se representa con doble cuerpo de campanas y chapitel. (Fig. 4).

Nos interesa la fisonomía de la torre de San Gil donde vemos que ya no tiene el campanil, le falta un cuerpo de campanas, y está rematada por un chapitel. Este chapitel corona la torre cuadrada, forma con la que arranca su cuerpo troncopiramidal inferior. No se aprecia, como en el caso del de Santa María, que tuviese en cada uno de sus cuatro faldones buhardas, es decir, ventanas que permitían salir a los tejados. Sí parece que en su cornisa tuviese cuatro pequeñas pirámides decorativas. Sobre la aludida estructura troncopiramidal se disponía un anillo emplomado del que arrancaba la aguja, rematada con bola, veleta y cruz (Fig.5).

Por ello entre 1565, o, mejor dicho, después de las intervenciones de 1567, y 1668, año de la acuarela de Baldi, la torre debió de sufrir transformaciones y, probablemente, se debió modernizar la maquinaria del reloj eliminando el campanil, un cuerpo de campanas, y

37 AHN. Sección Clero Secular-regular, Legajo 2109. Apéndice Documental documento 1. 


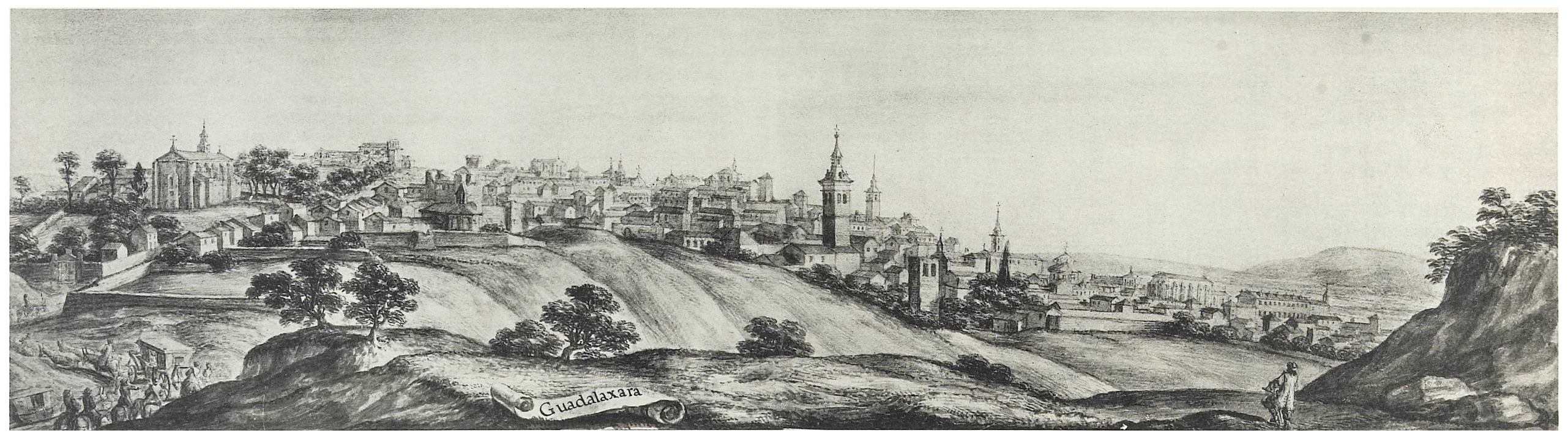

Fig. 4: Vista de la ciudad de Guadalajara.

Pier María Baldi, 1668. https://es.wikipedia.org/wiki/Archivo:Pier_Maria_Baldi_(1668)_Guadalajara.png

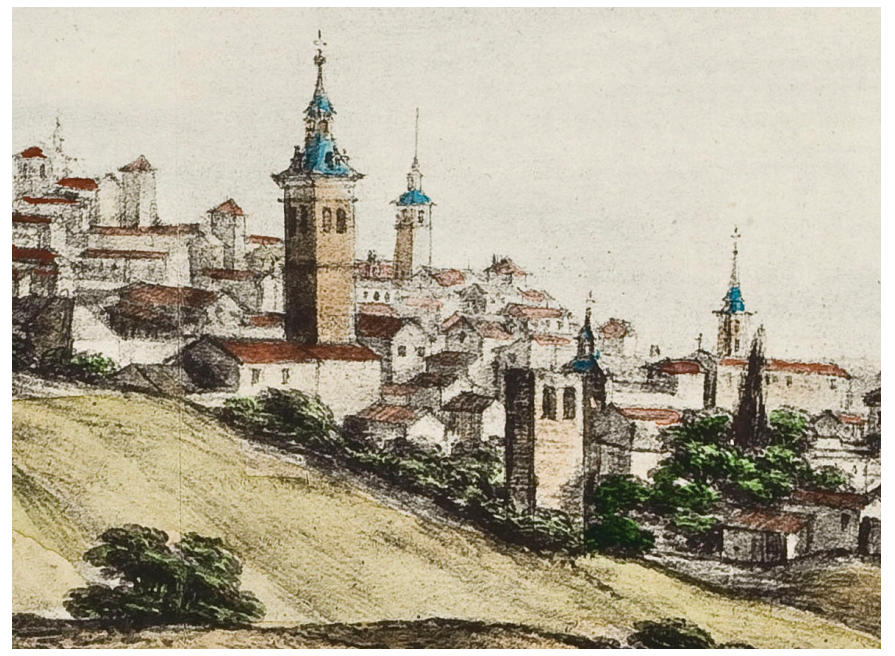

Fig. 5: Detalle de las torres de Santa María, San Gil y San Andrés. Pier María Baldi, 1668 https://es.wikipedia.org/wiki/Archivo:Pier_Maria_Baldi_(1668)_Guadalajara.png 
coronando la torre con el chapitel. Muy probablemente, estas obras pudieron llevarse a cabo a finales del siglo XVI por algunos de los maestros activos en la ciudad, quizá Juan de Ballesteros o Diego de Balera ${ }^{38}$. En cualquier caso, no se tiene constancia porque al ser obras que pagaba el ayuntamiento no se registraban en los libros de fábrica. Así, en el asiento de obra de fábrica de 1562 consta un pago de 9.000 maravedíes a favor de Pedro de Naveda, cantidad en la que se dató la obra de la puerta, es decir, la construcción del nuevo atrio $^{39}$.

En 1625 la torre de San Gil presentaba de nuevo problemas, pues se conserva un informe con las condiciones de lo que se debía de hacer en el chapitel y en su armadura, muy maltratada por las filtraciones del agua de lluvia pues, como veremos, estaba revestido de hojas de lata, láminas de hierro o acero estañadas por las dos caras. Las condiciones fueron presentadas por los maestros Diego de Yebes y Sebastián Pérez que estipularon la obra en el precio de 1.000 reales de vellón.

Lo primero que se había de hacer era recrecer en cuatro pies, unos 120 centímetros, la base sobre la que se iba a asentar la nueva cárcel, es decir, el telar que era el entramado o enrejado sobre el que apoyaba la armadura del chapitel. Además, se debía de hacer una nueva cárcel "porque la que ahora tiene esta toda podrida" ${ }^{40}$ por los clavos de la hoja de lata. Sobre este telar o pieza de asiento se colocaban directamente estribos al interior de la mitad de los muros. Para reforzar, se asentaban cuadrales en las esquinas y en la parte central dobles tirantes en cruz ensamblados a media madera. Los tirantes pareados formaban un hueco cuadrado central donde se asentaba el árbol, mientras que en los extremos se colocan los puentes, en línea con la cara interior del muro, donde se embarbillaban las tornapuntas. Desde esa base se iba ensamblando las limas, pares y péndolas y el primer entramado

38 Agradezco la apreciación del Dr. José Miguel Muñoz liménez. Estos maestros figuraban en las obras municipales y en el entorno del duque de Infantado. Ambos habían trazado chapiteles en la Universidad de Alcalá y en la Casa del Bosque de Buitrago de Lozoya, respectivamente.

39 MUÑOZ JIMÉNEZ, J.M.: "Repertorio documental de la arquitectura del manierismo en la ciudad de Guadalajara (1540-1635)". En: Wad-al-Hayara, 14, 1987a, pp. 61-136. De los datos documentales que aporta este autor se sabe que el pórtico se ejecutó al año siguiente, es decir, en 1563, cuando consta el pago de 8.499 maravedíes por la piedra, los ladrillos y los peones.

40 Condiciones de la obra del reloj y chapitel de la torre de San Gil, S.d-S.m. 1625, AHN, Sección Clero Secular-regular, Legajo 2109. Apéndice Documental, documento 2.
Luego se formaba un cuerpo de transición para armar la aguja mediante limas y pares ${ }^{41}$ Los maestros proponían revisar toda esta estructura para reponer las piezas que estuviesen deterioradas para tornarle "a texar a lomo çerrado para que quede firme"

El chapitel debía de tener encima de la cornisa cuatro pirámides que eran elementos ornamentales de poco relieve, como reminiscencias de los pináculos de las torres góticas de Flandes, "dos que se han de haçer de nuevo y las otras dos repararllas de forma que

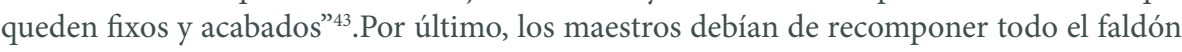
del chapitel aprovechando la hoja de lata que estuviese en buenas condiciones.

Respecto a los maestros que la ejecutaron, Diego de Yebes, activo entre 1606 y 1637 era un albañil y carpintero, que alcanzó el cargo de alarife del cabildo, y que, junto a sus hermanos, Gaspar y Juan, estuvo vinculado a las obras que se ejecutaron en la ciudad de Guadalajara $^{44}$. Por su parte Sebastián Pérez, documentado entre 1623 y 1625, intervino en el claustro de San Francisco de Guadalajara junto a otros maestros, como Juan Ramos, y en el transparente del retablo mayor de dicha iglesia conventual ${ }^{45}$. Como vemos, tanto Diego Yebes como Sebastián Pérez eran maestros del ámbito local que muy probablemente no pudieron hacerse con obras en un panorama constructivo muy competitivo dominado por maestros toledanos o madrileños del círculo de Juan Gómez de Mora. Por ello, se hicieron con obras menores como la recomposición de la armadura y hechura del chapitel de la iglesia de San Gil.

41 Para describir estas armaduras de madera hemos seguido a ESTEPA GÓMEZ, R.: Chapiteles del siglo XVI al XVIII en Madrid y su entorno: sus armaduras de madera. Tesis Doctoral, E.T.S. Arquitectura (UPM), 2015, pp. 347 y ss.

42 Condiciones de la obra del reloj y chapitel de la torre de San Gil, S.d-S.m. 1625, AHN, Sección Clero Secular-regular, Legajo 2109. Apéndice Documental, documento 2.

43 Condiciones de la obra del reloj y chapitel de la torre de San Gil, S.d-S.m. 1625, AHN, Sección Clero Secular-regular, Legajo 2109. Apéndice Documental, documento 2.

44 MUÑOZ JIMÉNEZ, J.M.: "La arquitectura del manierismo...", p.172.

45 Ibid., p.211 


\section{SU DECLIVE: SIGLOS XVIII AL XX}

La imagen que presenta la torre en las vistas de Baldi es la que mantuvo hasta el siglo XIX. No nos ha llegado noticias sobre obras o intervenciones en la misma durante el siglo XVIII. En cualquier caso, su estructura mudéjar tuvo que presentar problemas porque consta en 1895 un informe del arquitecto municipal de ese momento, Baldomero Botella, instando a su reparación urgente al haberse desprendido parte de la misma ${ }^{46}$.

Durante el siglo XIX se alude en varias ocasiones al estado ruinoso de su fábrica, como el 20 de abril de 1842, cuando ya se propone suprimirla. "... está denunciado como ruinoso y era necesario demolerte de todos modos y trasladar la Parroquia a San Nicolás, templo suntuoso por su hermosura ..."37. Diez años después, es decir, el 18 de marzo de 1852, se obliga al ayuntamiento a repararla, pues había recibido como contrapartida los restos de la demolida parroquia de San Andrés, y constan obras menores consistente en revoques, pintura o la instalación de una reja, según presupuesto del maestro Juan Antonio Pérez ${ }^{48}$. En 1855 las lluvias provocaron el hundimiento del tejado y la pared de una de las capillas alineadas con la torre ${ }^{49}$, reparaciones que no se acometieron hasta más tarde, una vez acordado con el ayuntamiento el presupuesto ${ }^{50} \mathrm{y}$ necesitar la mediación del gobernador civil $^{51}$, cuando se incluyen nuevos desperfectos que afectaban a la estabilidad de la torre ${ }^{52}$

46 Informe de Baldomero Botella sobre reparos en la torre de San Gil de Guadalajara, 16 de enero de 1895 Archivo Municipal de Guadalajara (AMGU), Leg. 786. Cit. PRADILLO Y ESTEBAN, P. J.: "La desaparecida parroquia...," p. 231

47 Propuesta para demoler la iglesia de San Gil de Guadalajara, 12 de mayo de 1842, AMGU, Libro de Actas Capitulares. Cit. PRADILLO Y ESTEBAN, P.J.: "La desaparecida parroquia...," p. 220.

48 Propuesta del albañil Juan Antonio Pérez para el reparo de la iglesia de San Gil de Guadalajara, 5 de mayo de 1852, AMGU, Leg. 793. Cit. PRADILLO Y ESTEBAN, P.J.: "La desaparecida parroquia..." p. 220

49 Daños sufridos en la iglesia de San Gil de Guadalajara, 11 de marzo de 1855, AMGU, Libro de Actas Capitulares. Cit. PRADILLO Y ESTEBAN, P.J.: “La desaparecida parroquia...," pp. 221.

50 Acuerdo con el Ayuntamiento para la reparación de la iglesia de San Gil de Guadalajara, 4 de diciembre de 1861, AMGU, Libro de Actas Capitulares. Cit. PRADILLO Y ESTEBAN, P.J.: "La desaparecida parroquia..., p. 221.Este autor señala que en el acuerdo el Ayuntamiento aportaba 10.013 reales y 17 maravedíes y el párroco renunciaba a la indemnización por los pies cedidos para alinear la capilla y los derechos sobre San Andrés.

51 Mediación del Gobernador Civil en el asunto de la iglesia de San Gil de Guadalajara, 20 de diciembre de 1862, Libro de Actas Capitulares. Cit PRADILLO Y ESTEBAN, PJ. “La desaparecida parroquia....” p. 222.

52 Bases de acuerdo entre el Ayuntamiento y el párroco de San Gil. 15 de enero de 1863, AMGU, Leg. 786 Cit. PRADILLO Y ESTEBAN, P.J.: "La desaparecida parroquia...," p. 222. De acuerdo con este autor, el nuevo presupuesto ascendía a 13.000 reales, al contemplar esta vez la indemnización por alinear la fachada de las capillas, y una adición de 1.400 reales por los desperfectos de la torre.
Hemos de pensar que fue en 1863 cuando con las reformas perdió su chapitel y quedó con una sencilla cubierta a cuatro aguas sostenida por modillones. No obstante, en 1895 la inestabilidad de su fábrica mudéjar se hacía patente por sus desprendimientos.

La situación del conjunto de San Gil no mejoró, ya que necesitaba profundas reformas estructurales y existen constantes peticiones de licencia al ayuntamiento para obras destinadas a afianzar su fábrica, que acaban con el acuerdo para su demolición firmado en 1921 y ejecutado en $1924^{53}$. Sólo quedarían en pie el arco de entrada, el ábside, la capilla de los Orozco y la torre (Fig.6). El total abandono hizo que, previa notificación a la Comisión

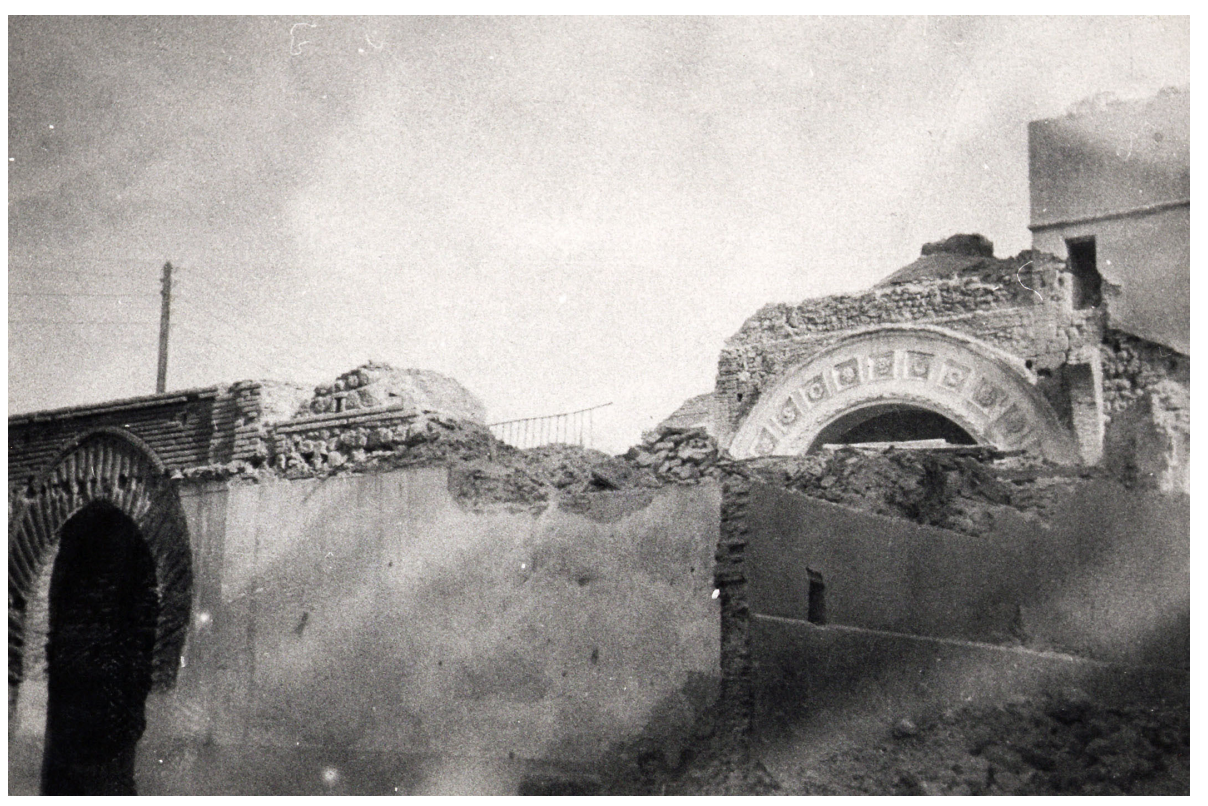

Fig. 6: Proceso de demolición de la iglesia de San Gil en Guadalajara. Foto Goñi. Ministerio de Cultura y Deporte. Archivo General de la Administración, fondo de Medios de Comunicación Social del Estado, IDD (03)084.000 caja F/00784, sobre 10

53 Acuerdo para el derribo de la iglesia de San Gil, 23 de febrero de 1921, AMGU, Libro de Actas Capitulares. Cit. PRADILLO Y ESTEBAN, P.J.: "La desaparecida parroquia...," p. 220. 
Provincial de Monumentos ${ }^{54}$, el 23 de junio de 1932 se derribasen la torre y la capilla de los Orozco, cuyas yeserías fueron salvadas, quedando en pie hasta su restauración actual la cabecera, el ábside y muros laterales.

\section{CONCLUSIÓN}

La torre de San Gil formó parte de un conjunto arquitectónico mudéjar levantado en torno al siglo XIV, construida con gruesos muros de mampostería revestidos de ladrillo. En esen cia su estructura debió ser un modelo parecido al de la torre de Santa María, constituyendo uno de los mejores ejemplos de la arquitectura bajomedieval en Guadalajara. A finales del siglo XV, por las necesidades que implicó la instalación del reloj municipal, la torre se vio ampliada con un cuerpo de vanos y una torreta a modo de campanil. Esta obra, junto a peso de la maquinaria del reloj, no debió favorecer la solidez de la torre. Quizá esta no estuviese preparada para soportar más carga o su estructura adicional fue tan mal construida que provocó su ruina. Se trata de dos hipótesis que se proponen a la vista del peritaje que hicieron los maestros de la época y del enrevesado informe para su reparación.

La vista de esta torre mudéjar es la que nos ofrece el dibujo de Wyngaerde en 1565 sobresaliendo, por encima del caserío urbano como hito arquitectónico y orgullo cívico al contener el reloj municipal. Pese a la idílica imagen, la torre ya tenía serios problemas estructurales por cuya reparación litigaron el poder civil y el eclesiástico, ganando los beneficiarios de la parroquia con la intervención del mismo Felipe II. Los informes que se emitieron nos permiten conocer los nombres de los maestros que en ese momento están trabajando en otras obras de la ciudad, lo que nos habla de las redes en la que se organizaban los maestros canteros del quinientos en Castilla. Del mismo modo, certificar que fueron obras para reforzar la estabilidad de la torre pero que no fueron suficientes. En cualquier caso, la torr albergó uno de los ejemplos de relojes medievales con autómata en su esfera y campana para marcar la hora como en otras ciudades castellanas y, por extensión, europeas. Este reloj permaneció en la torre hasta 1788 cuando se trasladó a la torreta del edificio municipal.

A finales del siglo XVI, de manos de algunos de los maestros que trabajaban en la ciudad o a las órdenes del duque del Infantado, la torre fue modificada con el añadido de un chapitel, la supresión de la torreta medieval, quizá una de la causante de la ruina de la torre, y la pérdida de un cuerpo de campanas. En 1625 los maestros Diego de Yebes y Sebastián Pérez rehicieron el chapitel y toda la estructura que lo envolvía, muy deteriorada por ser de hojalata y haber favorecido las filtraciones. El informe no sólo nos presenta un modelo de chapitel, que se corrobora en la vista de Baldi de 1668, sino que nos desgrana cómo se levantaban los esqueletos en madera que debían de soportar la estructura. Carecía de buhardas, pero sí tenía cuatro pequeñas pirámides que recordaban las viejas estructuras de los campanarios del gótico en el antiguo ducado de Brabante.

Al llegar al siglo XIX los problemas sobre la estabilidad de la torre continuaban. Ello nos permite concluir que la fábrica mudéjar no estaba bien asentada y que todas las obras que se emprendieron fueron "apaños" para reforzar su estabilidad geométrica. En torno a 1863 debido a los derrumbes, se debió desmontar su chapitel y cubrirla con un sencillo tejado a cuatro aguas.

La torre llegó al siglo XX despojada de la gloria de su pasado, suprimida como parroquia, y dejada de la mano de unas autoridades municipales más interesadas en alinear la planimetría de la vieja ciudad de los Mendoza que en conservar su rico pasado medieval. Los informes de Ramón Mélida no hicieron justicia y en Guadalajara no parecieron cuajar las teorías de la moderna restauración romántica francesa. En 1924, la parroquia era el resto de una ruina medieval en alberca, a la que tampoco se le aplicó las teorías de Ruskin, siendo completamente mutilada en 1932 cuando desapareció su torre. La desidia de las autoridades municipales acabó con la memoria de la torre que había tomado el pulso a la ciudad medieval y moderna.

54 El Ayuntamiento traslada a la Comisión Provincial de Monumentos el acuerdo alcanzado para el derribo de los restos de San Gil, 17 de agosto de 1931, AMGU, Libro de Actas Capitulares. 


\section{BIBLIOGRAFÍA}

ARACIL, A: Juego y Artificio. Madrid, Cátedra. 1998.

BENITO RUANO, E.: "Relojes y relojeros del ayuntamiento de Madrid en los siglos XV XVI", Anales del Instituto de Estudios Madrileños, tomo 3, 1968, 141-149.

ESTEPA GÓMEZ, R.: Chapiteles del siglo XVI al XVIII en Madrid y su entorno: sus armaduras de madera. Tesis Doctoral. 2015.

GARCÍA LÓPEZ, A.: "Datos artísticos inéditos sobre el maestro de obras morisco Acacio de Orejón (1519-d.1574)”, Wad-al-Hayara, no 20, 1993, 265-290.

LAYNA SERRANO, F.: Historia de Guadalajara y sus Mendozas en los siglos XV y XVI. Tomo I, segunda edición. Guadalajara, AACHE ediciones, 1993.

LE GOFF, J.: La civilización del occidente medieval. Barcelona, Paidós, 1999.

LÓPEZ VILLALBA, J.M.: Las Actas de Sesiones del Concejo Medieval de Guadalajara. Madrid, Universidad Nacional de Educación a Distancia, 1997.

MEJÍA ASENSIO, A.: "Apuntes para una mejor comprensión de la evolución urbana de la ciudad de Guadalajara en los inicios de la Edad Moderna (1491-1531)", actas, XI Encuentro de Historiadores del Valle del Henares, Guadalajara, Diputación Provincial de Guadalajara, 2008, 553-576.

MUÑOZ JIMÉNEZ, J.M.: “De la ciudad medieval a la ciudad del Siglo de Oro: análisis de la transformación urbanística y arquitectónica de Guadalajara (1550-1650”, Wad-al-Hayara $\mathrm{n}^{\circ} 13,1986,357-375$

MUÑOZ JIMÉNEZ, J.M.: La arquitectura del manierismo en Guadalajara. Guadalajara Institución Provincial de Cultura "Marqués de Santillana", 1987.

MUÑOZ JIMÉNEZ, J.M.: Repertorio documental de la arquitectura del manierismo en la ciudad de Guadalajara (1540-1635)", Wad-al-Hayara, n 14, 1987a, 61-136.

MUÑOZ JIMÉNEZ, J.M.: "Iconografía y topografía: análisis de la Vista de Guadalajara de Antonio de las Viñas y de otras dos vistas barrocas sobre lo mismo", actas, III Encuentro de Historiadores del Valle del Henares, Guadalajara, Diputación Provincial de Guadalajara, 1992, 673-689.
PAVÓN MALDONADO, B. “Guadalajara medieval. De la ciudad árabe a la cristiana. Testimonios arqueológicos”, en IX Centenario de la conquista de Guadalajara. MITRE, E., BA LLESTEROS, P. y PAVÓN MALDONADO, B. (Eds.), Guadalajara, Patronato Municipal de Cultura de Guadalajara, 1998, 27-52.

PÉREZ DE TUDELA, M.a T.: "Madrid en la documentación de Santo Domingo el Real”, en La ciudad hispana durante los siglos XIII al XVI. SÁEZ SÁNCHEZ, E., SEGURA GRAÍÑ̃O C. y CANTERA MONTENEGRO, M. ${ }^{a}$ (Eds.), Madrid, Universidad Complutense de Madrid, 1998, 991-1010.

PRADILLO Y ESTEBAN, P. J.: “La desaparecida parroquia de San Gil de Guadalajara: Estado de la cuestión y nuevas aportaciones", Wad-al-Hayara, nº 21, 1994, 211-256.

PRADILLO Y ESTEBAN, P. J.: “Organización del espacio urbano en la Guadalajara medieval”, Wad-al-Hayara, n 26, 1999,17-55

QUADRADO FUENTE, J. M.a: Guadalajara y Cuenca. Barcelona, Ediciones el Albir, 1978.

REDONDO CANTERA, M.a J.: "El reloj de la iglesia riosecana de Santa Cruz, obra de maestros burgaleses", Boletín de la Institución Fernán González, n² 212, 1996, 99-106.

ROMERO BEJARANO, M.: "Francisco de Heredia, maestro entallador, y la autoría de Cristo de la Viga de San Salvador de Jerez de la Frontera", Laboratorio de Arte, nº.16, 2003 , 381-398.

ROMERO BEJARANO, M.: "Santas cosas son llamadas los muros. La arquitectura militar en Jerez durante el siglo XVI”. Jerez de la Frontera, Servicio de Publicaciones del Ayuntamiento de Jerez de la Frontera, 2008.

SÁNCHEZ DE CASTRO, J.:"Mudejarismo en Guadalajara (siglos XIII-XV)”, Wad-al-Hayara, $\mathrm{n}^{\circ} 12,1985,145-156$.

TORRES BALBÁS, L.: “Arte almohade, arte nazarí y arte mudéjar”, en Ars Hispaniae, IV. Madrid, Plus Ultra, 1949.

TRALLERO SANZ, A.M.: "La iglesia de San Gil de Guadalajara”, Archivo Español de Arte, vol. $88, \mathrm{n}^{\circ} 350,2015,113-130$. 


\section{APÉNDICE DOCUMENTAL}

Doc. 1. Sobre los reparos que son necesarios acometer en la torre de San Gil, 30 de julio de 1565 y 9 de octubre de 1566, Archivo Histórico Nacional, Madrid, Sección Clero Secular-regular, Legajo 2109.

En el ayuntamiento que se tuvo en esta ciudad de Guadalajara treinta días del mes de julio de mill y quinientos y sesenta e çinco años por los muy magníficos señores licenciado Her nando Becerra corregidor en la dicha ciudad e tierra por su majestad e Gaspar Gutiérrez de Porras e Luis de la Bastistada e Lope de Lasarte de Molina e Francisco de Bustamante regidores e Diego de Molina jurado por ante mi Alonso Lopez escribano de su magestad del concejo e ayuntamiento e número de la dicha ciudad e su tierra por merçed de su magestad presento la petición de suso contenida el dicho marcos gomez cura de san Gil y por mi el dicho escribano leída a sus mercedes dijeron que los señores Francisco de Guzmán e Lope de Lasarte regidores lo vean e averigüen y hagan relación delo ante mi Alonso Lopez escribano.

La obra que manda hazer el ylustre ayuntamiento de esta ciudad en la torre de la yglessia del señor San Gil a la parte donde esta el relox es lo siguiente

Primeramente se an de maçiçar los dos arcos del campanario de la esquina donde esta el relox que están quebrantados y abiertos el uno que cae hacia el corral de la yglessia y el otro que cae por donde sube la cadena del relox de yeso e ladrillo haciendo sus ligaçones en lo viejo muy acusado al remate maçiçando todos los agujeros que oviere en esta esquina de yesso y ladrillo muy maçiço.

Otrosi se ha de hechar una viga desde la esquina donde esta el relox hasta el relox (sic) hasta la esquina que cae al corral embebida en los pilares de ladrillo por partes de dentro de la torre que siente encima del can donde esta el relox y pase de cada pilar de la esquina pie y medio así como de de las esquinas del relox como de la parte del corral y de cada parte de esta se echen dos clavizas de hierro de una vara de medir en largo cada una que sean gruesas a contento del ayuntamiento o del caballero que fuese comisario esta viga a de ser terçia e quarta de yeso.

A se de maçiçar desde encima de los arcos donde esta viga se pone todo el grueso del arco y suba deste mismo grueso y asta encima de la viga una tercia de yeso y canto o yeso y ladrillo lo que el maestro que esta obra hiciere quisiere echar
Otrosi se hechen dos quadrales en los dos rincones de esta viga de diez pies de rincon e ocho e mas que los gruesos de las paredes pasen de toda partes muy bien tomadas con sus yesos y clavados en la parte de la viga.

Otrosi se a de adereçar el hombre de lata echando unas piernas de madera nueva y guarneçedle de lata y adereçar el tabladillo donde esta el relox puesto y retejar el tejado y todas las cosas que fuere menester tocantes al relox de yeso o madera se an de adereçar

Otrosi hallamos que tiene necesidad de echar otras dos vigas la una encima del otro can que se de largo e grueso de otra que esta escripta y que esta viga pase el grueso de la torre la cámara del relox y entiendese que la otra que cae hacia el corral ha de pasar por debajo de la cámara y con su claviza como es dicho e tiene mucha necesidad hacia la parte de la calle echar otra viga conforme estas otras con sus clavizas y estas tres vigas se encadenen por entramas partes.

El maestro que esta obra tomare lo a de hazer a toda costa sin dar la ciudad ninguna cosa mas que los dineros en que se rematare muy bien acabada en perfección a vista de maestros que de ello entiendan.

Doc. 2. Condiciones de la obra del reloj y chapitel de la torre de San Gil. S.d-S.m. 1625. Archivo Histórico Nacional, Madrid, Sección Clero Secular-regular, Legajo 2109.

Memoria y condiciones de lo que se ha de hazer en el chapitel y harmadura de la torre de esta ciudad.

Primeramente, se han de hechar quatro pies corriendo el macizo de abaxo para rescreçer la armadura que al presente esta hecha por cuanto esta todas las çarceles que al presente estan hechos maltratados de las aguas.

Es condiçion que se ha de haçer una carcel donde carga el texado que aora al presente esta porque la que ahora tiene esta toda podrida.

Es condiçion que se ha de destexar todo el texado alrrededor y echar todas las tablas que fueren nescessarias y algunos maderos en la armadura y tornarle a texar a lomo çerrado para que quede firme.

Es condiçion que las quatro piramides que aora al presente estan las dos se han de haçer de nuevo y las otras dos repararllas de forma que queden fixos y acabados. 
+ del dicho chapitel. Es condicion que todo el chapitel desde la cornisa arriba se ha de deshaçer y tornarle a haçer de nuevo con su faldon conforme al que al presente tiene porque el que aora tiene se a podrido y no se puede defixar cosa alguna en ello.

Es condiçion que el maestro que desto se encargue a de aprovechar la lata que al presente tiene y todo lo demas que faltare lo a de poner y madera y clavaçon y no le an de dar mas de solamente el dinero que se conçertare y asimismo a de poner la texa y tablas neçessarias al texado y todo esto se a de obligar a dexallo acabado conforme a las condiçiones dichas y la persona que pusiera la çiudad para que vea si esta cumplido conforme a lo contratado.

Yo Diego de Yebes y Sebastian Perez hemos visto este adereço del chapitel y hallamos que segun las condiçiones lo haremos y cumpliremos por preçio de mill reales y lo firmamos de nuestros nombres. 